June 2003 • NREL/CP-500-33465

\title{
Identification of Wind Turbine Response to Turbulent Inflow Structures
}

\section{Preprint}

\author{
M.M. Hand \\ N.D. Kelley
}

National Renewable Energy Laboratory

M.J. Balas

University of Colorado

To be presented at the $4^{\text {th }}$ ASME/JSME Joint Fluids Engineering Conference Honolulu, Hawaii June 6-10, 2003

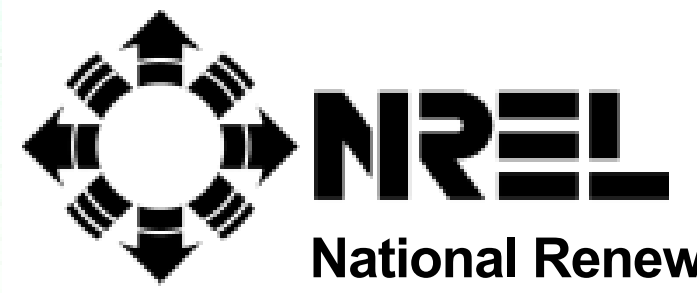

1617 Cole Boulevard Golden, Colorado 80401-3393

NREL is a U.S. Department of Energy Laboratory Operated by Midwest Research Institute $\bullet$ Battelle $\bullet$ Bechtel Contract No. DE-AC36-99-G010337 


\section{NOTICE}

The submitted manuscript has been offered by an employee of the Midwest Research Institute (MRI), a contractor of the US Government under Contract No. DE-AC36-99G010337. Accordingly, the US Government and MRI retain a nonexclusive royalty-free license to publish or reproduce the published form of this contribution, or allow others to do so, for US Government purposes.

This report was prepared as an account of work sponsored by an agency of the United States government. Neither the United States government nor any agency thereof, nor any of their employees, makes any warranty, express or implied, or assumes any legal liability or responsibility for the accuracy, completeness, or usefulness of any information, apparatus, product, or process disclosed, or represents that its use would not infringe privately owned rights. Reference herein to any specific commercial product, process, or service by trade name, trademark, manufacturer, or otherwise does not necessarily constitute or imply its endorsement, recommendation, or favoring by the United States government or any agency thereof. The views and opinions of authors expressed herein do not necessarily state or reflect those of the United States government or any agency thereof.

Available electronically at http://www.osti.gov/bridge

Available for a processing fee to U.S. Department of Energy and its contractors, in paper, from:

U.S. Department of Energy

Office of Scientific and Technical Information

P.O. Box 62

Oak Ridge, TN 37831-0062

phone: 865.576.8401

fax: 865.576.5728

email: reports@adonis.osti.gov

Available for sale to the public, in paper, from:

U.S. Department of Commerce

National Technical Information Service

5285 Port Royal Road

Springfield, VA 22161

phone: 800.553 .6847

fax: 703.605.6900

email: orders@ntis.fedworld.gov

online ordering: http://www.ntis.gov/ordering.htm

Printed on paper containing at least $50 \%$ wastepaper, including $20 \%$ postconsumer waste 


\section{IDENTIFICATION OF WIND TURBINE RESPONSE TO TURBULENT INFLOW STRUCTURES}

\author{
M. Maureen Hand \\ National Wind Technology Center \\ National Renewable Energy Laboratory \\ 1617 Cole Blvd. MS 3811 \\ Golden, Colorado 80401 USA \\ Ph: (303) 384-6933 \\ Fax: (303) 384-6901 \\ maureen_hand@nrel.gov
}

\author{
Mark J. Balas \\ Aerospace Sciences Center \\ University of Colorado \\ 429 UCB \\ Boulder, Colorado 80309-0429 USA \\ Ph: (303) 492-3177 \\ Fax: (303) 492-7881 \\ mark.balas@colorado.edu
}

Neil D. Kelley

National Wind Technology Center

National Renewable Energy Laboratory

1617 Cole Blvd. MS 3811

Golden, Colorado 80401 USA

Ph: (303) 384-6923

Fax: (303) 384-6901

neil_kelley@nrel.gov

\section{ABSTRACT}

The National Renewable Energy Laboratory conducted an experiment to obtain detailed wind measurements and corresponding wind turbine measurements in order to establish a causal relationship between coherent turbulent structures and wind turbine blade fatigue loads. Data were collected for one entire wind season from October 2000 to May 2001. During this period, the wind turbine operated under atmospheric conditions that support the formation of coherent turbulent structures $31 \%$ of the time. Using the equivalent fatigue load parameter as a measure of wind turbine blade fatigue and using statistical measures of the turbulent fluctuations of the wind, general correlation between the turbulence and the wind turbine response is shown. Direct correlation cannot be resolved with 10-minute statistics for several reasons. Multiple turbulent structures can exist within a 10-minute record, and the equivalent fatigue load parameter is essentially a 10 -minute statistic that cannot estimate turbine response to individual turbulent structures. Large-magnitude turbulent fluctuations in the form of instantaneous Reynolds stresses do not necessarily correspond directly to large-magnitude blade root moment amplitudes. Thus, additional work must be done to quantify the negative turbine response and to correlate this response to turbulent inflow parameters over time scales less than 10 minutes.

Keywords: wind turbines, turbulence, fatigue

\section{INTRODUCTION}

In order to maximize energy capture at lower annual average wind speed sites, wind turbines are being placed on towers approaching $100 \mathrm{~m}$ in height. At this hub-height, rotors encounter turbulence with characteristics that differ from that experienced at lower levels. Thus rotors are susceptible to greater fatigue damage that results from turbulence. A better understanding of these turbulence effects is necessary if the current 20- to 30-year design life criteria are to be maintained.

Understanding the basic characteristics of these turbulent structures is essential if advanced control schemes are to be developed to mitigate loads. This investigation focuses on the rotor/inflow interaction that results from embedded coherent turbulent structures in an attempt to quantify those events that give rise to the largest transient loads. Once identified, it is presumed that simplified, analytic representation of the inflow can be used to develop control paradigms for load mitigation. These simplified models of the turbulent structure would serve as disturbance models for wind turbine controllers based on 
Disturbance Accommodating Control theory. In essence, the effect of the disturbance - the turbulent structure - can be mitigated through active control of blade pitch angle, for instance.

To establish the causal relationship between these coherent turbulent structures and the wind turbine response, an experiment was undertaken by the National Renewable Energy Laboratory (NREL). Detailed wind measurements along with turbine measurements were made upwind of and on the $600-\mathrm{kW}$ advanced research turbine (ART) at NREL's National Wind Technology Center near Golden, Colorado. Data were collected during an entire wind season from October 2000 through May 2001 , in which the predominant wind direction is $292^{\circ}$ from true North.

Figure 1 depicts the wind turbine and the upwind planar array. Using the wind turbine load response, the corresponding turbulent inflow was examined in order to identify the primary characteristics of the turbine/inflow interaction.

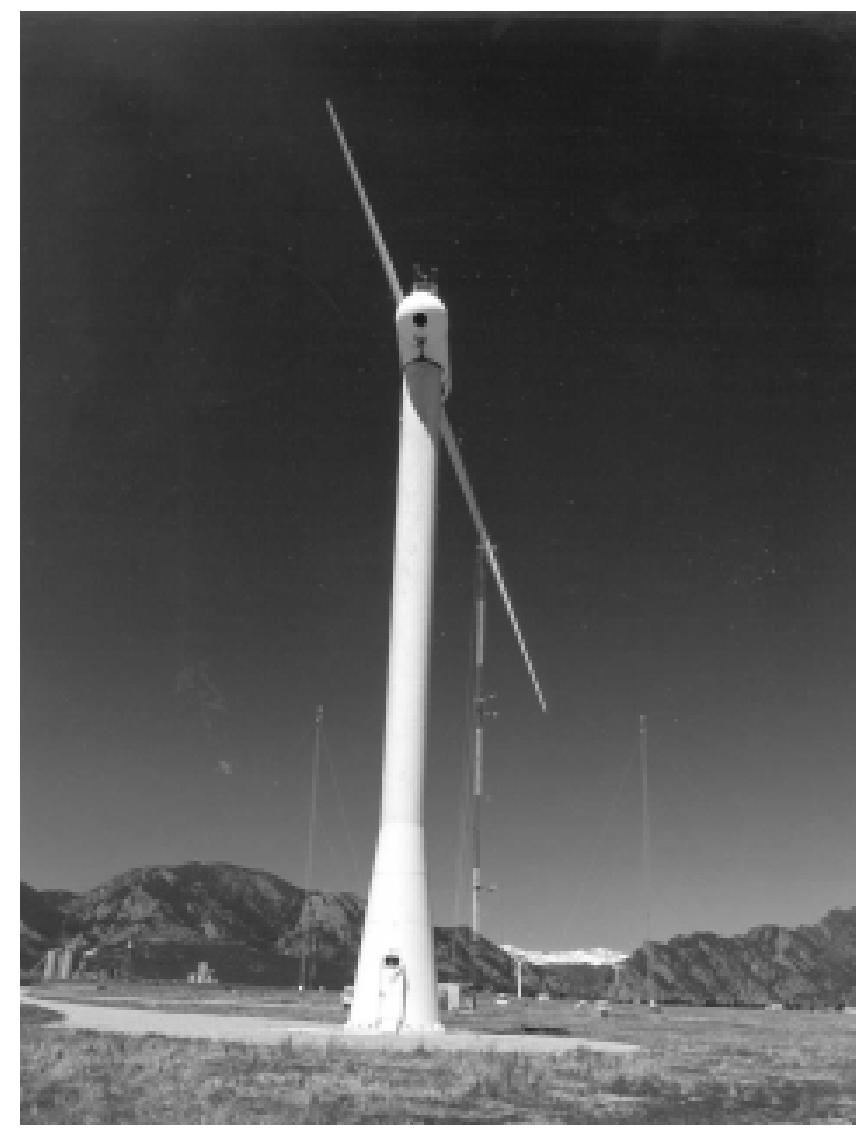

Figure 1. The ART turbine with planar array in the primary upwind direction.

\section{NOMENCLATURE}

$F=$ amplitude of the ith cycle counting bin, $\mathrm{kNm}$

$F_{e}=$ equivalent fatigue load, $\mathrm{kNm}$

$$
\left[\frac{\sum_{i}\left(F_{i}\right)^{m} n_{i}}{N_{o}}\right]^{\frac{1}{m}}
$$

$g=$ gravity acceleration, $\mathrm{m} / \mathrm{s}^{2}$

$i=$ number of cycle counting bins (222)

$m=$ material constant, exponent for the S-N curve (10 for fiberglass composite material)

$n=$ number of rainflow cycles in the ith bin

$N=$ number of samples $(24,000$ samples per 10 -minute record at $40 \mathrm{~Hz}$ )

$N_{o}=$ cycles over 10-minute period (840)

$R i=$ Richardson Number

$$
\left(g / \overline{\theta_{\mathrm{m}}}\right)\left(\Delta \overline{\theta_{\mathrm{v}}(z)} / \Delta z\right)(\Delta \overline{U(z)} / \Delta z)^{-2}
$$

$t=$ time

$T I=$ turbulence intensity, $(\%)$,

$$
\frac{\sigma_{U}}{\overline{U(z)}}
$$

$T K E=$ turbulence kinetic energy, $(\mathrm{m} / \mathrm{s})^{2}$,

$$
\frac{1}{2}\left[\left(u^{\prime}\right)^{2}+\left(v^{\prime}\right)^{2}+\left(w^{\prime}\right)^{2}\right]
$$

$\overline{U(z)}=$ mean horizontal inflow velocity at height $z$

$u^{\prime}, v^{\prime}, w^{\prime}=$ streamwise, crosswind, and vertical instantaneous component velocities in a right-handed coordinate system where the longitudinal or streamwise wind component is parallel to the mean streamline, $\mathrm{m} / \mathrm{s}$

$u^{\prime} w^{\prime}, u^{\prime} v^{\prime}, v^{\prime} w^{\prime}=$ turbulent Reynolds stress components, $(\mathrm{m} / \mathrm{s})^{2}$

$u^{\prime} w^{\prime}=$ vertical momentum flux, $(\mathrm{m} / \mathrm{s})^{2}$

$w^{\prime}(T K E)=$ vertical flux of turbulence kinetic energy, $(\mathrm{m} / \mathrm{s})^{3}$

$w^{\prime} \theta_{v}^{\prime}=$ vertical heat flux, K-m/s

$\bar{X}=$ mean value of $\mathrm{X}$ over time period $\mathrm{t}$, for number of samples, $\mathrm{N}$ 
$\overline{\theta_{m}}=$ mean virtual potential temperature (between $3 \mathrm{~m}$ and $61 \mathrm{~m}), \mathrm{K}$

$\overline{\theta_{v}(z)}=$ mean virtual potential temperature at height $\mathrm{z}, \mathrm{K}$

$\theta_{v}^{\prime}=$ virtual potential temperature instantaneous fluctuation component, $\mathrm{K}$

$$
\theta_{v}(t)-\overline{\theta_{v}}
$$

$\sigma_{x}=$ standard deviation of $\mathrm{X}$

\section{EXPERIMENTAL DATA}

The wind turbine is a 43-m diameter, two-bladed, upwind machine. The hub teeters to relieve the varied wind load across the rotor. Strain gauge measurements include blade root flap and root edge bending moment on each blade, as well as lowspeed shaft torque. Absolute position encoders measured rotor azimuth position, teeter angle, yaw angle, and blade pitch angle. Generator power was also recorded. An inertial measurement unit (IMU) was installed on the forward bearing where the lowspeed shaft enters the gearbox. This device provided accelerations in three orthogonal directions, as well as rotation rate about each of the axes. This data system sampled at 512.8 $\mathrm{Hz}$, and 20-Hz, six-pole, low-pass Butterworth filters were used on all analog signals. The data was decimated to 80 samples per second before being stored. Records of 10 minutes in length were collected, resulting in 3,299 total records from the turbine data system.

A second data system, consisting of a planar array situated $53 \mathrm{~m}$ upwind of the turbine, was used to measure the wind inflow. Five high-resolution ultra-sonic anemometers/thermometers were situated on three towers at positions corresponding to the perimeter of the rotor-swept area and at the hub height, as shown in Figure 2. Additional wind speed and wind direction measurements were obtained on the central tower using cup anemometers and wind vanes. Air temperature, fast-response temperature, temperature difference, and dew point temperature sensors were installed on the central tower. Barometric pressure was measured at a height of $3 \mathrm{~m}$. The inflow system was sampled at $40 \mathrm{~Hz}$, resulting in a Nyquist frequency of $20 \mathrm{~Hz}$. Records of 10 minutes in length were collected, resulting in 6,791 total records from the inflow system. This system collected data during periods in which the turbine was not in operation due to high wind cutoff.

Post-processing routines further reduced the turbine data to $40 \mathrm{~Hz}$ for merging with the corresponding inflow records. Further detail may be found in Kelley et al. [1]. A total of 2,818 10-minute records represent the merged database. Of this set, 1,569 records represent data in which the turbine operated throughout the duration of the record and the mean wind direction remained within $\pm 45^{\circ}$ of the perpendicular to the planar array.

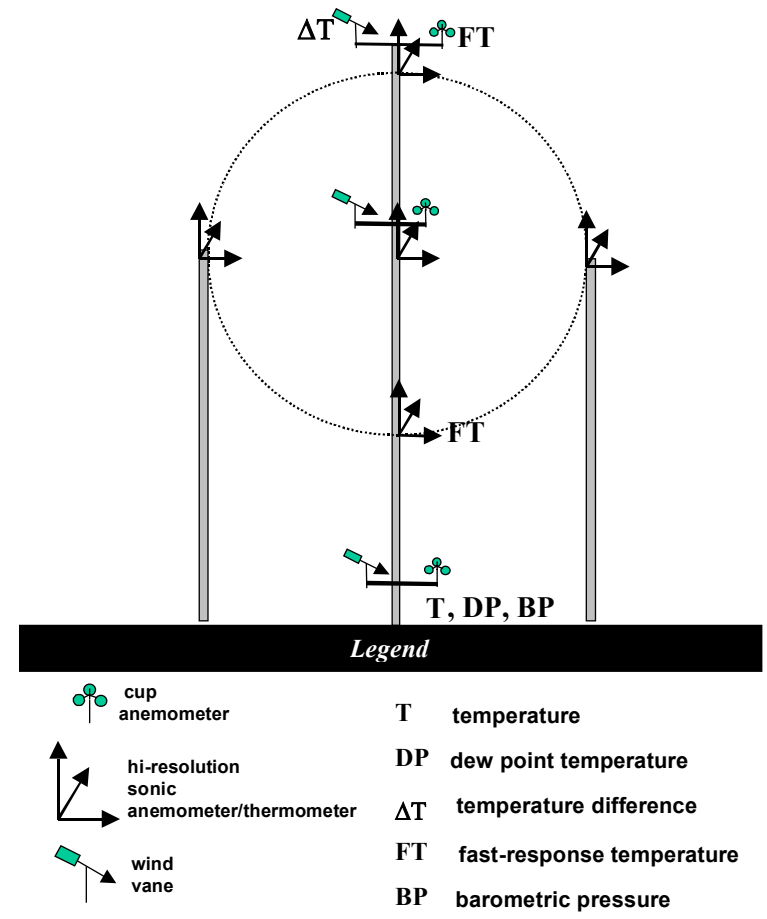

Figure 2. Inflow array instrumentation deployment.

\section{INFLOW TURBULENCE GENERATION}

The planetary boundary layer is divided into several different layers that radically change throughout the diurnal cycle. The layer near the ground is the surface layer, bounded above by the mixed layer during the day and by the nocturnal, or stable, boundary layer at night. The depth of each layer grows and shrinks as the dynamic stability promotes or restricts the development of turbulence.

Likewise, the static stability of the atmosphere also follows a strongly diurnal pattern. During the day, the atmosphere is statically unstable with homogeneous turbulence due to thermal mixing. The depth of the surface layer can vary from 100 to $150 \mathrm{~m}$ during the daylight hours. The surface layer is characterized by near-constant vertical flux of momentum with height and positive (upward) heat flux during the day. Turbulence is generated primarily due to convection, with largescale convective circulations forming in the mixed layer.

During the night, the boundary layer becomes statically stable with turbulence constrained by negative buoyancy. The surface layer depth can vary from 10 to $50 \mathrm{~m}$ and is characterized by negative (downward) heat flux and near constant downward flux of momentum with height. Under the proper conditions, the stable boundary layer may support the formation of Kelvin-Helmholtz billows, internal gravity waves, and low-level jets $[2,3]$. Turbulence is generated as a result of the mean shear accompanying the thermal stratification and the overturning and breakdown of waves within the layer. It is transported throughout the layer by various mechanisms. 
The atmospheric conditions that can support turbulence generation in the stable boundary layer were identified in the experimental data. The gradient Richardson number $(R i)$, a dimensionless representation of the atmospheric dynamic stability, is positive in stable atmosphere conditions. Additionally, negative heat flux, or transport of warmer air toward the ground, is a characteristic of the stable boundary layer. Vertical gradients in heat flux and vertical momentum flux (or the $v^{\prime} w$ ' Reynolds stress; see nomenclature) are additional characteristics of the stable boundary layer that forms above the surface layer (the surface layer is characterized by near-constant vertical gradients in heat flux and vertical momentum flux). Records in which the gradient of vertical momentum flux and heat flux across the rotor exceeds $10 \%$ of the mean indicate that the layer is stratified, i.e. not the surface layer. Of the 1,569 collected 10 -minute records, $31 \%$ of the records represent atmospheric conditions that meet the above stable boundary layer criteria. Thus the turbine operates in conditions that can support the formation of turbulent structures for a significant portion of a typical wind season.

\section{CORRELATION OF LOADS AND TURBULENCE}

Turbulent fluctuation about the mean wind causes load fluctuations that affect the fatigue life of the blade. Wavelet analysis was used by Kelley et al. [4] to demonstrate the role of coherent turbulence structures (as revealed by the Reynolds stress field) as a contributor to large load excursions. The equivalent fatigue load parameter $\left(F_{e}\right)$ is currently the wind industry's primary measure used to quantify these amplitude variations observed over a 10-minute time period in relation to the fatigue damage attributed to the fluctuations [5-7]. Essentially, the equivalent fatigue load weights each cyclic variation of the load over the 10-minute record using Miner's Rule. The equivalent fatigue load represents a constantamplitude, sinusoidal load applied at a constant rate (in this case 84 cycles/minute or 2 cycles per rotor revolution) over a 10-minute period that would cause equivalent fatigue damage to that sustained by the fluctuating load amplitudes resulting from the wind. In this study, a rainflow cycle counting routine [8] was used to count full cycles.

Figure 3 illustrates the mean hub-height wind speed as a function of the Richardson number, or atmospheric stability. Because the Richardson number is computed using 10-minute averaged values, it represents the background or mean state of the atmosphere over a time period. As the wind speeds increase, the atmospheric stability approaches neutral conditions $(R i=0)$ because thermal gradients dissipate as shear increases.

A similar correlation between blade flap equivalent fatigue load and atmospheric stability is shown in Figure 4. The colors represent the wind speed classifications delineated in Figure 3. The highest mean wind speeds (in red) do not correspond to the highest equivalent fatigue loads. This corroborates the notion that turbulent fluctuations about the mean contribute to blade load fluctuations that correspond to fatigue damage. It is also important to note that the highest equivalent fatigue loads occur at low, positive values of the Richardson number. In other words, the turbulence that affects the wind turbine blade fatigue loads primarily occurs under slightly stable atmospheric conditions. Similar results were reported by Kelley [9] using a different blade fatigue indicator.

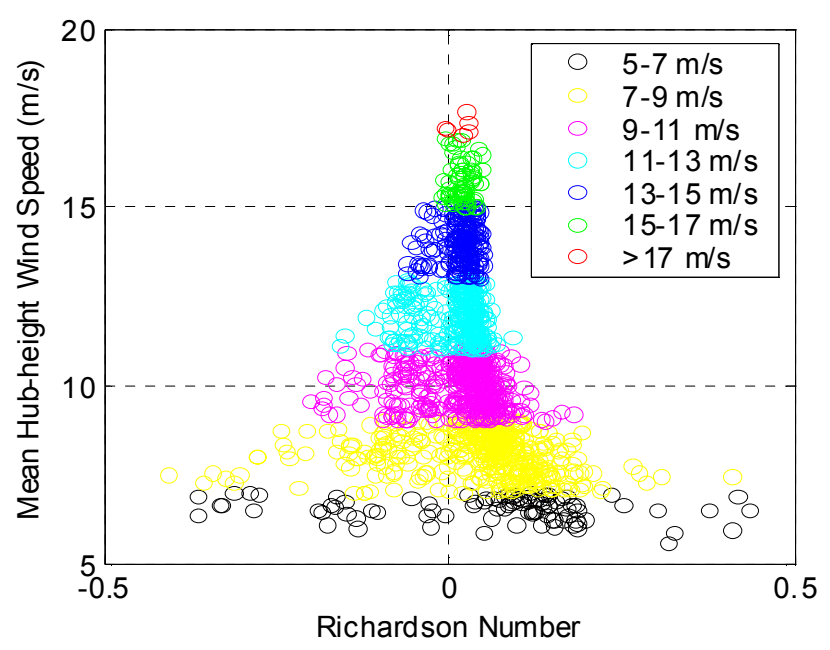

Figure 3. Ten-minute average, hub-height, wind speed as a function of atmospheric stability, Ri.

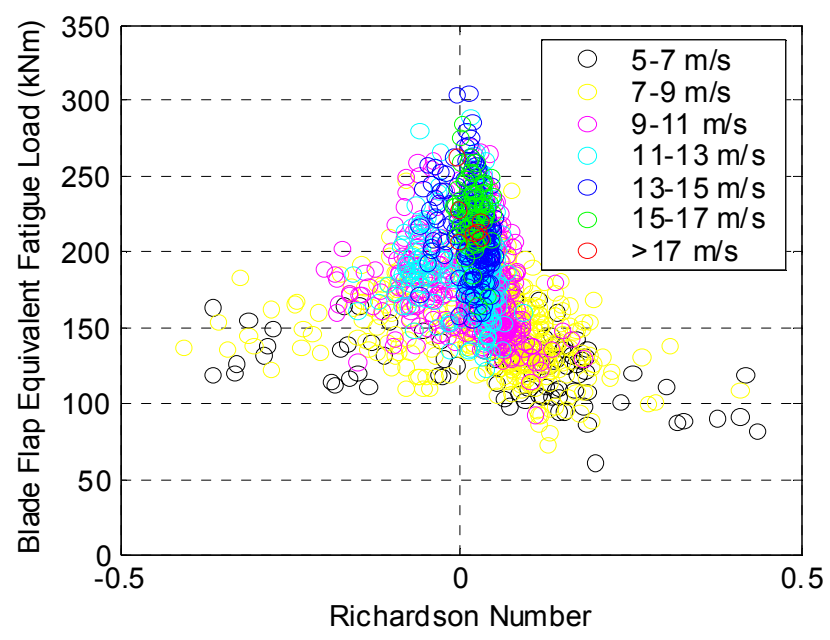

Figure 4. Blade root flap bending moment equivalent fatigue load as a function of atmospheric stability, Ri.

To quantify the turbulent fluctuations about the mean, inflow streamline fluctuation parameters $u^{\prime}, v^{\prime}$, and $w^{\prime}$ are used. Using a coordinate system translation to align the sonic anemometer component measurements with the mean streamline, the turbulent fluctuations about the mean are determined. The Reynolds stress components that consist of combinations of the primary components $\left(u^{\prime} w^{\prime}, u^{\prime} v^{\prime}\right.$, and $\left.v^{\prime} w^{\prime}\right)$ suggest rotation of the flow at the point where the measurement is made. 

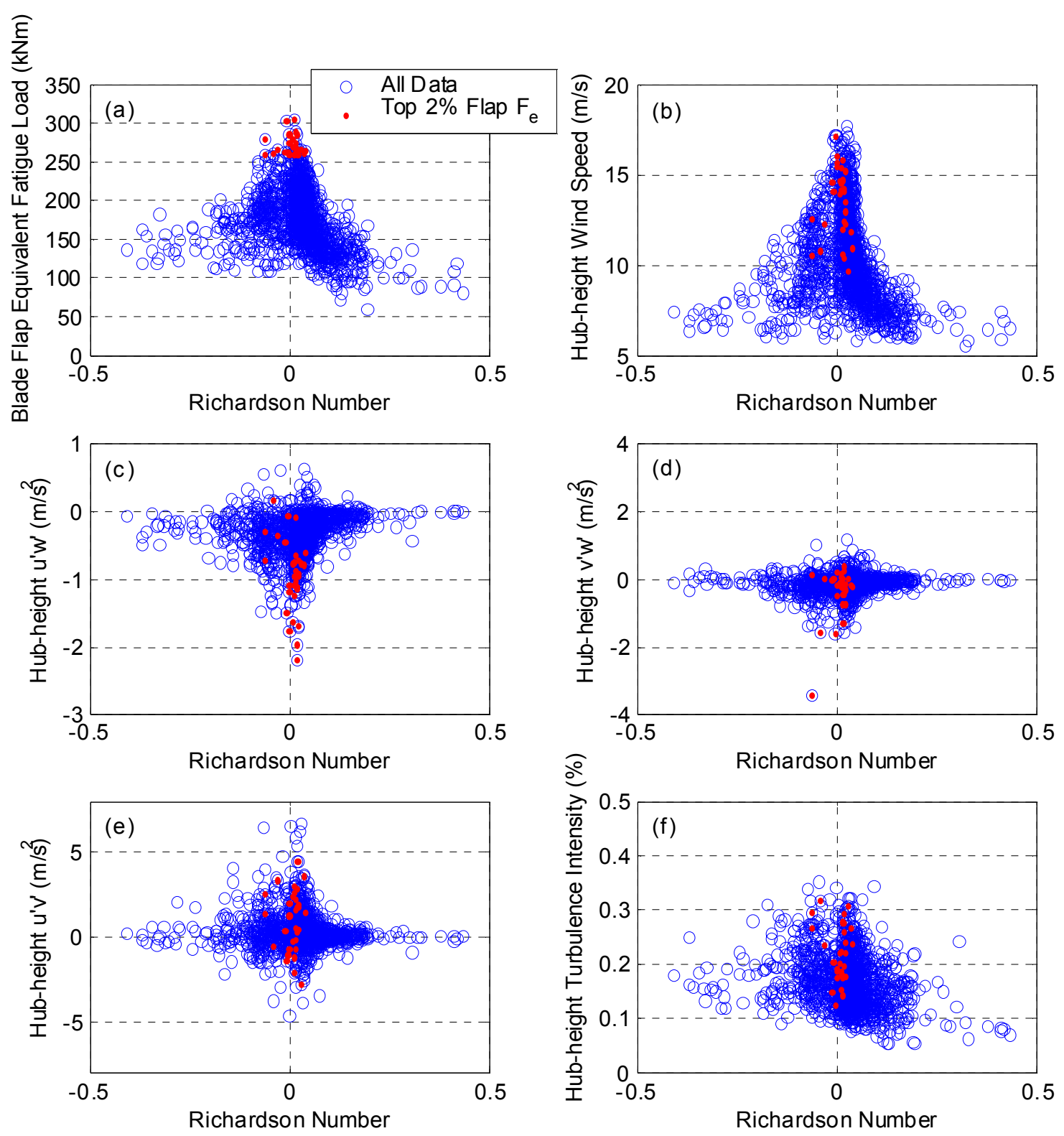

Figure 5. Top $2 \%$ blade flap equivalent fatigue load in relation to balance of database. Inflow parameters represent 10minute mean values from hub-height anemometer.

Figure 5 a shows the top $2 \%$ blade flap equivalent fatigue loads as a function of atmospheric stability in relation to the blade flap equivalent fatigue loads for the entire database. Again, hub-height wind speed is not a strong indicator of the top equivalent fatigue loads as shown in Figure 5b. The mean Reynolds stress components are shown in Figures $5 \mathrm{c}$-e. The Reynolds stress values with the highest magnitudes tend to occur in slightly stable atmospheric conditions, but these peaks are not strongly correlated with the top equivalent fatigue loads. A commonly used measure of turbulence, the turbulence intensity (shown in Figure 5f), also does not provide a strong correlation. Others have used 10-minute statistics to show that the vertical and lateral wind components, sometimes in the form of Reynolds stresses, are related to elevated equivalent fatigue loads $[5,6,7,10]$. However, Figure 5 indicates that 10minute statistics are not sufficient for developing a causal relationship between a turbulent event and the wind turbine response. Further examination of the time-series signals supports this observation.

An example of a 10-minute record corresponding to one of the top $2 \%$ equivalent fatigue load cases is presented in Figure 6 . The Reynolds stresses in Figure $6 \mathrm{~b}$ suggest multiple 
(a) Disk-average Wind Speed

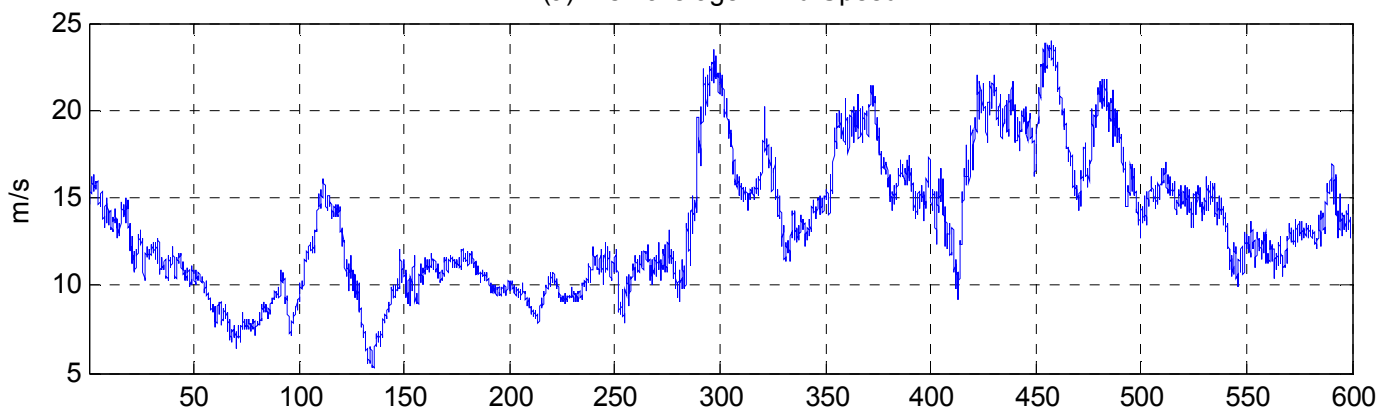

(b) Reynolds Stresses

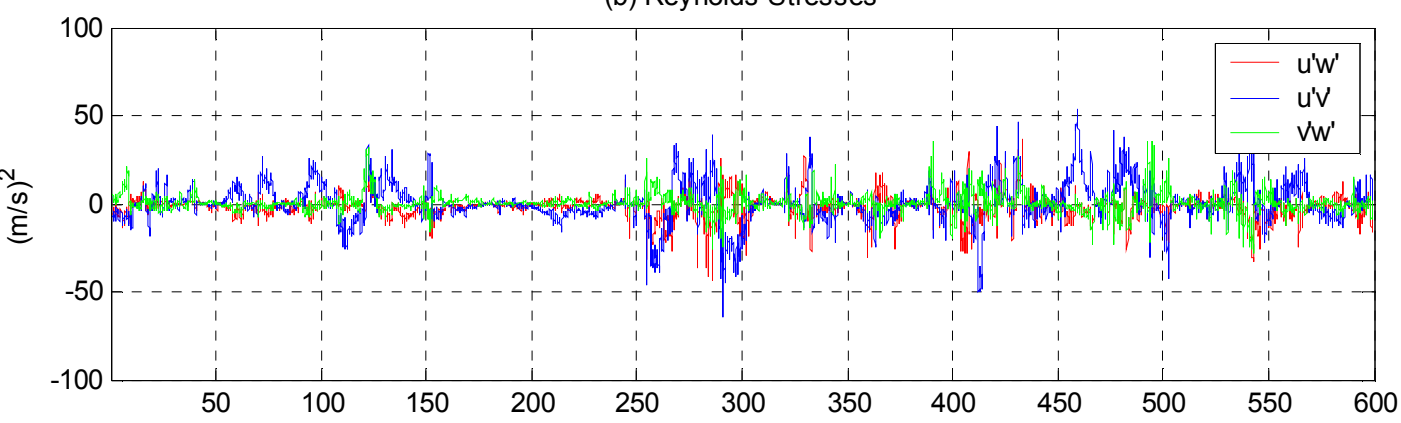

(c) Zero-mean Root Flap Bending Moment

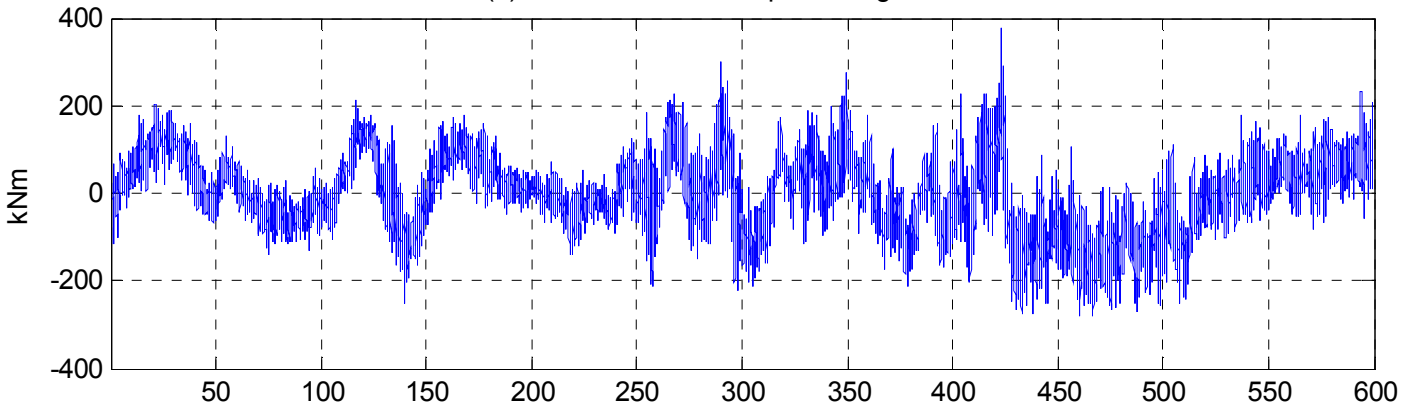

(d) Blade Pitch Angle

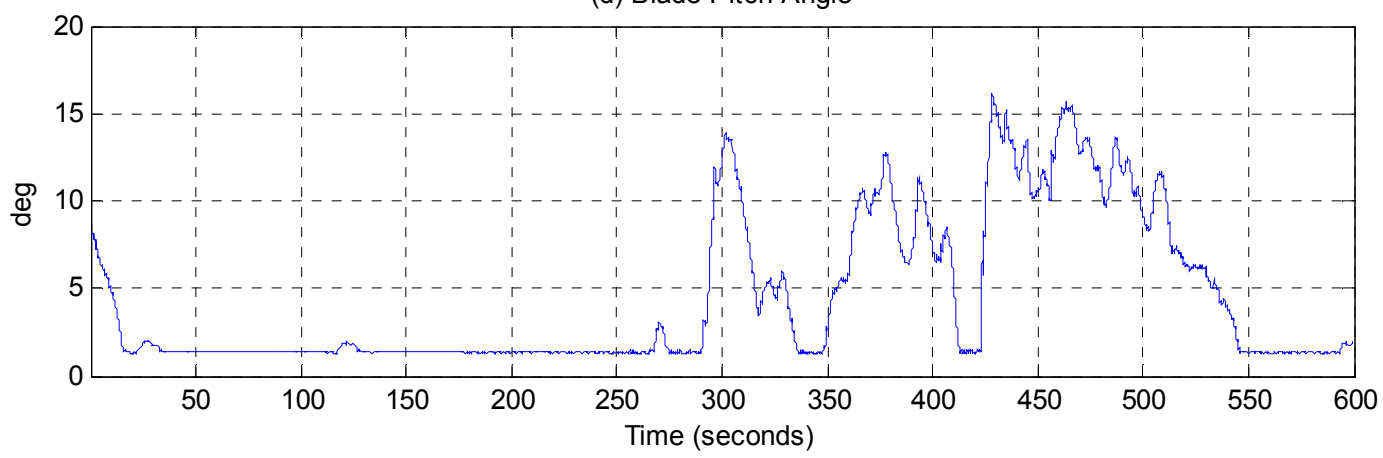

Figure 6. Ten-minute record showing turbulent "events" and turbine response. Data collected on February 5, 2001 at 0605 UTC. 


\begin{tabular}{|c|c|c|c|c|c|c|}
\hline File name & $\begin{array}{c}\text { Time } \\
\text { within } \\
\text { record }\end{array}$ & $\begin{array}{c}\text { Highest } \\
\text { magnitude } \\
u^{\prime} w^{\prime} \\
(\mathrm{m} / \mathrm{s})^{\wedge} 2\end{array}$ & $\begin{array}{c}\text { Highest } \\
\text { magnitude } \\
u^{\prime} v^{\prime} \\
(\mathrm{m} / \mathrm{s})^{\wedge} 2\end{array}$ & $\begin{array}{c}\text { Highest } \\
\text { magnitude } \\
v^{\prime} w^{\prime} \\
(\mathrm{m} / \mathrm{s})^{\wedge} 2\end{array}$ & $\begin{array}{c}\text { Root flap } \\
\text { bending } \\
\text { moment } \\
\text { range } \\
\text { (kNm) }\end{array}$ & $\begin{array}{c}\text { Root flap } \\
\text { equivalen } \\
\text { fatigue } \\
\text { load } \\
\text { (kNm) }\end{array}$ \\
\hline 02050605 & $50-175 s$ & 20 & 33 & 32 & 466 & 287 \\
\hline \begin{tabular}{|l|}
12190900 \\
\end{tabular} & $425-485 \mathrm{~s}$ & 34 & 91 & 47 & 511 & 276 \\
\hline 02050605 & $250-300 s$ & 44 & 65 & 26 & 521 & 287 \\
\hline 12190900 & 25-100s & 32 & 42 & 44 & 524 & 276 \\
\hline 02050505 & $480-550 \mathrm{~s}$ & 110 & 129 & 65 & 621 & 238 \\
\hline 02050605 & $380-500 s$ & 37 & 54 & 36 & 658 & 287 \\
\hline
\end{tabular}

Table 1. Comparison of turbulence parameters and load indicators for turbulent "events"

turbulent "events" within the 10-minute record. When the Reynolds stress magnitudes are not zero for short duration, the cyclic amplitude variation of the root flap bending moment increases. The equivalent fatigue load for this record is 287 $\mathrm{kNm}$. A histogram of the equivalent fatigue loads for the entire population is shown in Figure 7. Table 1 compares three "events" within the time series presented in Figure 6 (shaded rows) with three other "events." They are sorted according to the root flap bending moment range over the time period of each "event." This range is used in computing the equivalent fatigue load - the higher the range, the higher the equivalent fatigue load. Note that the highest bending moment range corresponds to one of three "events" within a 10-minute record. This also corresponds to the record with the highest equivalent fatigue load. However, the record with the lowest equivalent fatigue load contains a single, large, "event" that produces a significant bending moment range. Because the equivalent fatigue load is computed over a 10-minute record, a single, large "event" surrounded by many low range cycles may appear to result in significant fatigue damage. Also, the equivalent fatigue load computed over a 10-minute period cannot distinguish between multiple "events" within a record. It is essentially a 10-minute statistic that does not lend itself to determination of a causal relationship between turbulent inflow properties and the corresponding blade load response.

This wind turbine uses full-span blade pitch control to regulate generator power when the wind speed produces generator power in excess of $600 \mathrm{~kW}$. As the blade pitch increases, the flap bending moment decreases according to design. This is illustrated in Figure $6 \mathrm{c}$ and $6 \mathrm{~d}$ just prior to 300 $\mathrm{s}$ and near $425 \mathrm{~s}$. The equivalent fatigue load computation will include the load reduction that results from blade pitch changes. This "mean shift" in the root flap bending moment signal that results from power regulation through blade pitch adjustments complicates the turbine response to turbulent fluctuations. A different approach to quantifying fatigue damage must be developed in order to establish the direct correlation between turbine response and inflow turbulence.

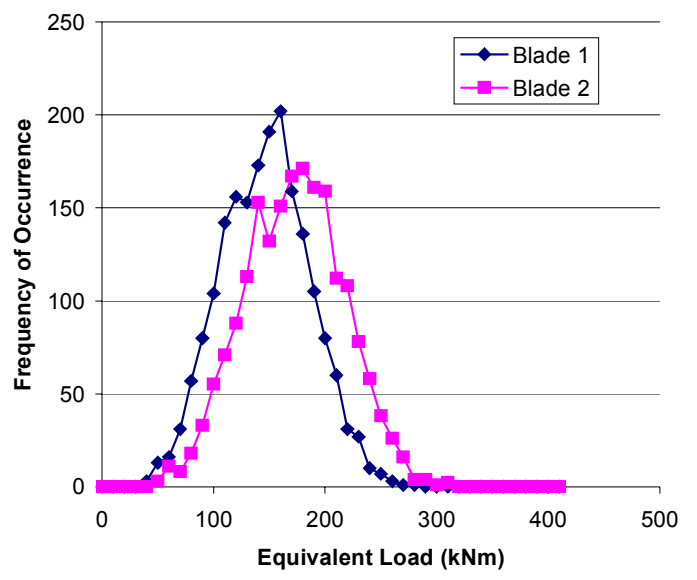

Figure 7. Histogram of equivalent fatigue load population.

Another important consideration is the magnitude of the turbulence fluctuation components - the deviations from the mean value over the 10-minute record. Averaging over a different period would produce different fluctuation values. When attempting to use 10-minute statistics to establish a correlation between a turbulent inflow structure and the turbine response, peak values appear to be valuable. The peak absolute value of each Reynolds stress is included in Table 1. The highest magnitude Reynolds stresses do not correspond to the highest root flap bending moment range. Even within the same record, the highest bending moment range does not correspond to the highest magnitude Reynolds stresses. Based solely on the magnitude of Reynolds stresses, the single "event" record should produce a significantly larger load than all the other examples, but it does not. 


\section{SPATIAL VARIATION OF TURBULENT STRUCTURES}

A more detailed examination of the turbulent structures that are associated with large blade responses suggests that the scale of the structure is comparable to the rotor scale or larger. Figures 8 and 9 contain time series traces of the Reynolds stresses at each anemometer for particular "events" that occurred under stable boundary layer conditions. As noted in the figure caption, an offset is added to each anemometer signal to reduce overlap of the traces on the plots. The turbulent fluctuations extend from the top $(58 \mathrm{~m})$ to the bottom $(15 \mathrm{~m})$ anemometers and from the North $(37 \mathrm{~m})$ to the South $(37 \mathrm{~m})$ anemometers. Figure 8 represents the second "event" listed in Table 1, and Figure 9 represents the sixth "event" (also shown in Figure 6). The Reynolds stresses at the bottom of the rotor tend to be somewhat muted from those at higher levels, suggesting that the turbulent structure weakens as it approaches the surface. Because the structure is seen in all five signals, its scale probably exceeds that of the rotor. Similar features at all five positions are apparent in each of the Reynolds stress components. This suggests that the fluid contains similar rotational components at each of the five anemometers, which indicates the coherent nature of the structure. The strength of the structure at the higher levels indicates that it was generated above the turbine rotor and is dissipating as it moves toward the ground.

The blade loading that corresponds to that shown in Figure 9 is contained over the same time period (380-480s) of Figure 6. The blade experiences a large cycle at about $425 \mathrm{~s}$. The Reynolds stress field contains fluctuations that begin at about $400 \mathrm{~s}$ and continue to $440 \mathrm{~s}$, which corresponds to the same time period in which the blade load cycle occurs. There is a time delay between the inflow signals at the array upwind of the turbine and the signals at the turbine itself that varies with the convection rate. However, the correlation between high load events and turbulence is evident. The load response that corresponds to the inflow shown in Figure 8 is similar, although it is not presented here.

The vertical flux of turbulence kinetic energy represents the vertical transport of turbulent energy. Figures $8 \mathrm{~d}$ and $9 \mathrm{~d}$ illustrate this. The magnitude of the vertical flux of turbulence kinetic energy at the top of the rotor exceeds that at the bottom of the rotor. Negative flux indicates transport of turbulence kinetic energy down toward the ground. This characteristic is indicative of atmospheric conditions (stable boundary layer) that support the generation of turbulence above the surface layer.

\section{CONCLUSIONS AND FUTURE WORK}

Field data indicate that turbulence causes increased fatigue loads on wind turbine blades. Under some atmospheric conditions, the turbulence can be generated above the surface layer and transported down to the rotor level. The atmospheric conditions supporting turbulence production through dynamic instabilities occur during a significant percentage of the turbine operation regime. The equivalent fatigue load parameter does not correlate turbulent "events" and turbine response because it is based on a 10-minute period. These "events" were observed to occur at much shorter periods on the order of 10-100s.

Cycle counting routines commonly used by the wind turbine industry to estimate fatigue damage are designed to select important features of the time-series but neglect the time history. Different criteria for determining fatigue-related load amplitudes in relation to turbulent events must be found. Some possibilities include amplitude range over time periods on the order of seconds or variation in standard deviation of root bending moments over similar time periods. These methods focus on the amplitude fluctuations of the bending moment that correspond to turbulent indicators.

Development of analytic models of potential turbulent structures will be necessary for control algorithm design. Further correlation of turbulent structures using the spatial resolution available from this experiment will yield insight into the shape and size of these structures. Mitigation schemes using advanced control methods will then be pursued.

\section{ACKNOWLEDGMENTS}

This work was funded by the Department of Energy (DOE) under contract DE-AC36-99GO10337. This material is declared a work of the U.S. Government and is not subject to copyright protection in the United States. The authors express gratitude to E. McKenna, S. Larwood, G. Johnson and S. Wilde for their roles in obtaining the experimental data.

\section{REFERENCES}

[1] Kelley, N., Hand, M., Larwood, S., and McKenna, E., 2002, "The NREL Large-Scale Turbine Inflow and Response Experiment - Preliminary Results," 2002 ASME Wind Energy Symposium, AIAA/ASME, pp. 412-426.

[2] Newsom, R.K. and R.M Banta, 2001, "Shear-Instability Gravity Waves in the Stable Nocturnal Boundary Layer as Observed by Doppler Lidar CASES-99," J. Atmos. Sci. (submitted).

[3] Stull, R.B., 1988, An Introduction to Boundary Layer Meteorology, Kluwer Academic Publishers, Dordrecht, The Netherlands.

[4] Kelley, N.D., Bialasiewicz, J.T., Osgood, R.M., and A. Jakubowski, 2000, "Using Wavelet Analysis to Assess Turbulence/Rotor Interactions," Wind Energy, 3, p.121-134.

[5] Fragoulis, A.N., 1997, "The Complex Terrain Wind Environment and Its Effects on the Power Output and Loading of Wind Turbines," 1997 ASME Wind Energy Symposium, AIAA/ASME, pp. 33-40.

[6] Mounturb Final Report, 1996, G. Glinou and A. Fragoulis, eds., 3 vols., JOU2-CT93-0378. 
[7] Sutherland, H.J., 2002, "Inflow and the Fatigue of the LIST Wind Turbine," 2002 ASME Wind Energy Symposium, AIAA/ASME, pp. 427-437.

[8] SAE Fatigue Design Handbook, 1997, R. Rice ed., $3^{\text {rd }}$ edition, Warrendale, PA: Society of Automotive Engineers, $470 \mathrm{p}$.
[9] Kelley, N.D., 1994, “The Identification of Inflow Fluid Dynamics Parameters that can be Used to Scale Fatigue Loading Spectra of Wind Turbine Structural Components," 1994 ASME Wind Energy Symposium, AIAA/ASME, pp. 181196.

[10] Sutherland, H.J., Kelley, N.D., and Hand, M.M., 2003, "Inflow and Fatigue Response of the NWTC Advanced Research Turbine," 2003 ASME Wind Energy Symposium, AIAA/ASME, pp. 214-224.

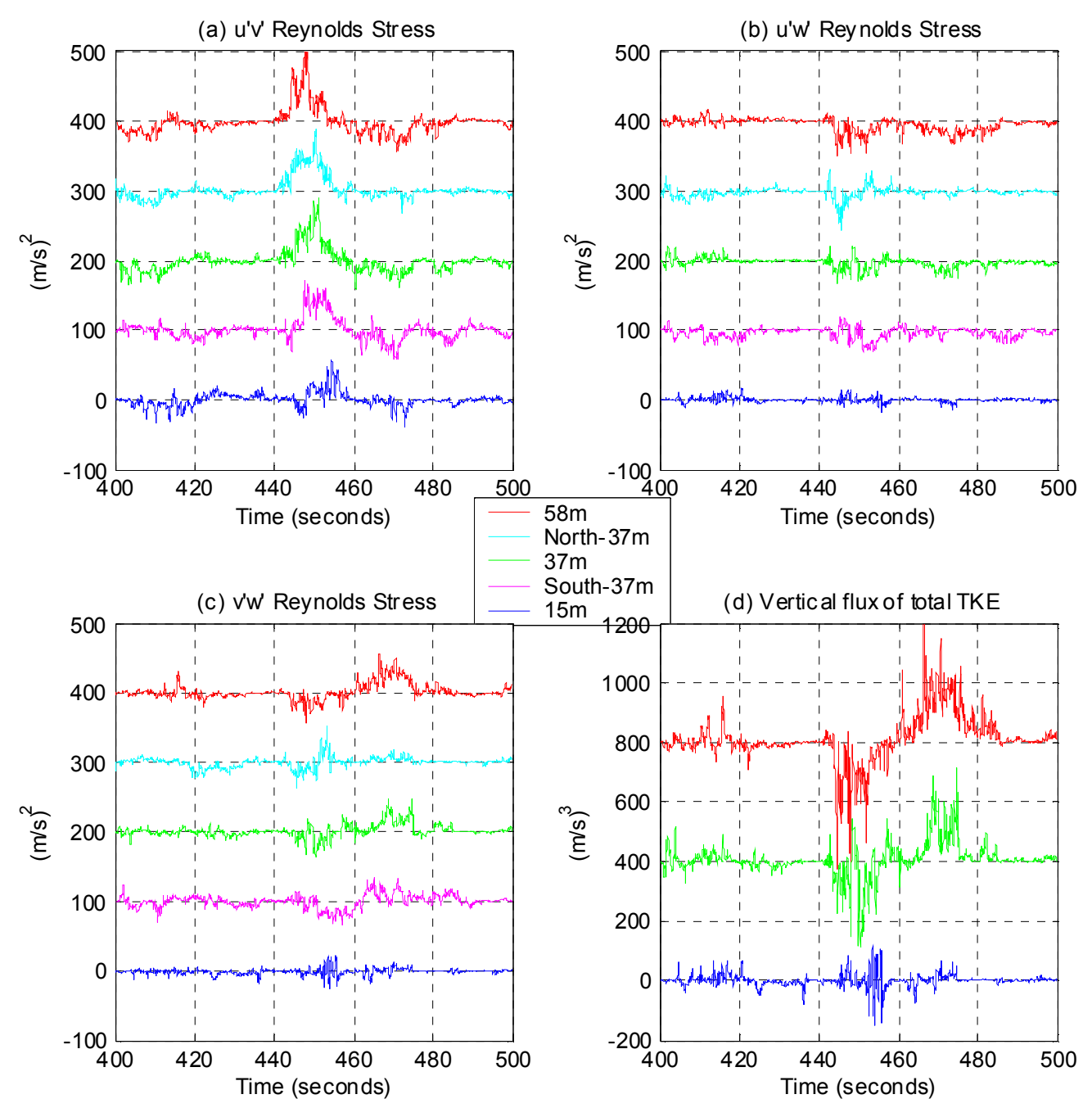

Figure 8. Spatial variation of turbulent structure and vertical flux of total TKE. Each trace offset from zero for clarity [58m $+400(\mathrm{~m} / \mathrm{s})^{2}$ or $800(\mathrm{~m} / \mathrm{s})^{3}$; North $+300(\mathrm{~m} / \mathrm{s})^{2} ; 37 \mathrm{~m}+200(\mathrm{~m} / \mathrm{s})^{2}$ or $400(\mathrm{~m} / \mathrm{s})^{3}$; South $\left.+100(\mathrm{~m} / \mathrm{s})^{2}\right]$. Data collected December 12 , 2000 at 0900 UTC. 
(a) u'v' Reynolds Stress

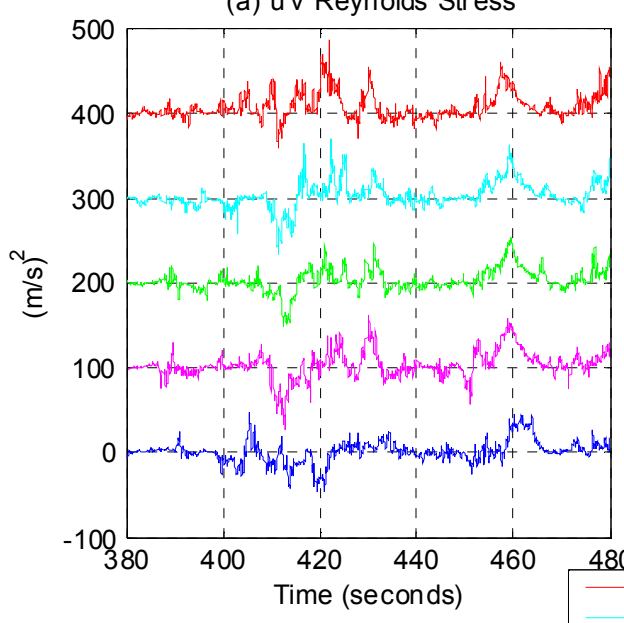

(c) v'w' Reynolds Stress

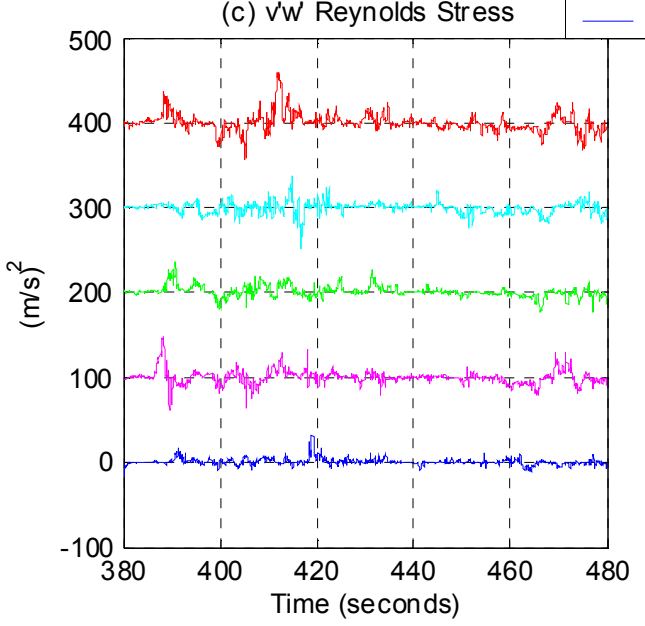

(b) u'W Reynolds Stress

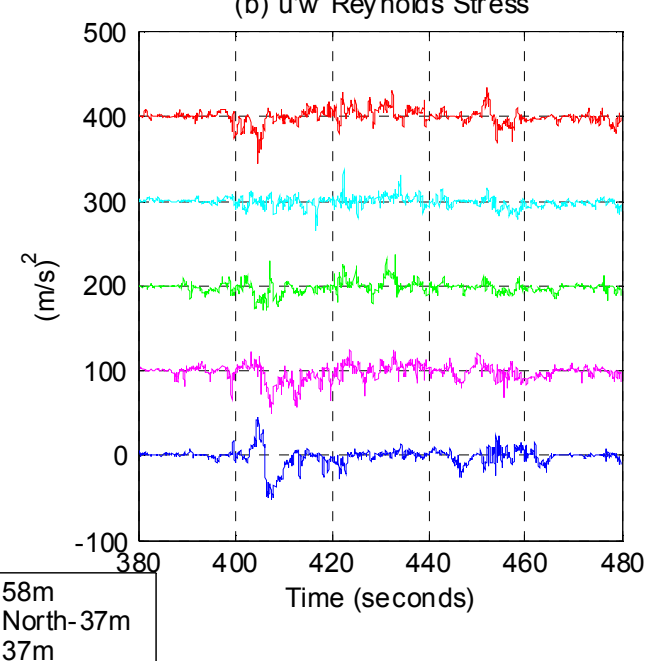

(d) Vertical flux of total TKE $5 \mathrm{~m}$

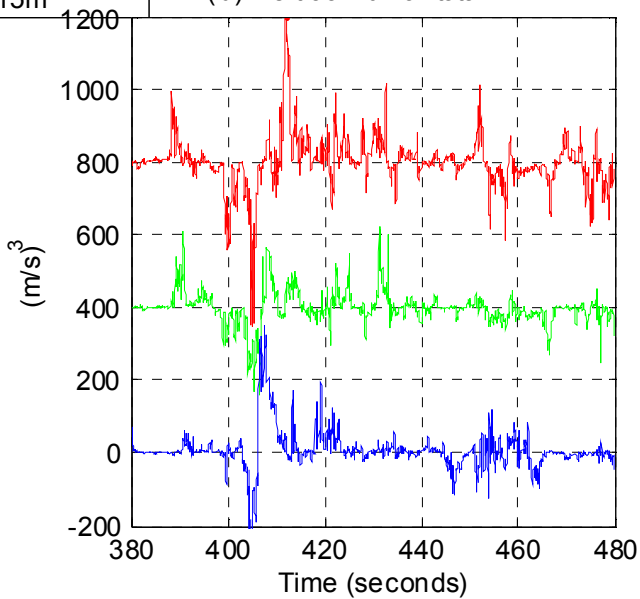

Figure 9. Another example of spatial variation of turbulent structure and vertical flux of total TKE. Each trace offset from zero for clarity $\left[58 \mathrm{~m}+400(\mathrm{~m} / \mathrm{s})^{2}\right.$ or $800(\mathrm{~m} / \mathrm{s})^{3}$; North $+300(\mathrm{~m} / \mathrm{s})^{2} ; 37 \mathrm{~m}+200(\mathrm{~m} / \mathrm{s})^{2}$ or $400(\mathrm{~m} / \mathrm{s})^{3}$; South $\left.+100(\mathrm{~m} / \mathrm{s})^{2}\right]$. Data collected February 5, 2001 at 0605 UTC. 
Public reporting burden for this collection of information is estimated to average 1 hour per response, including the time for reviewing instructions, searching existing data sources,

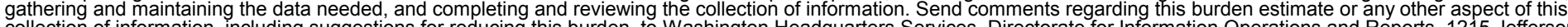

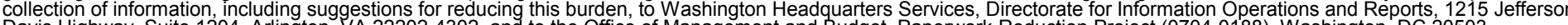
Davis Highway, Suite 1204, Arlington, VA 22202-4302, and to the Office of Management and Budget, Paperwork Reduction Project (0704-0188), Washington, DC 20503.

\begin{tabular}{|l|l|l|}
\hline 1. AGENCY USE ONLY (Leave blank) & $\begin{array}{l}\text { 2. REPORT DATE } \\
\text { June } 2003\end{array}$ & $\begin{array}{l}\text { 3. REPORT TYPE AND DATES COVERED } \\
\text { Conference paper }\end{array}$ \\
\hline
\end{tabular}

4. TITLE AND SUBTITLE
Identification of Wind Turbine Response to Turbulent Inflow Structures: Preprint

5. FUNDING NUMBERS

6. $\operatorname{AUTHOR}(\mathrm{S})$

M.M. Hand, N.D. Kelley, M.J. Balas

WER3.1940

WER2.1010

\title{
7. PERFORMING ORGANIZATION NAME(S) AND ADDRESS(ES) National Renewable Energy Laboratory \\ 1617 Cole Blvd. \\ Golden, CO 80401-3393
}

9. SPONSORING/MONITORING AGENCY NAME(S) AND ADDRESS(ES)

8. PERFORMING ORGANIZATION REPORT NUMBER NREL/CP-500-33465

\author{
9. SPONSORINGIMONITORINGAGENCYNAME(S) ANDADDRESS(ES)
}

10. SPONSORING/MONITORING AGENCY REPORT NUMBER

\section{SUPPLEMENTARY NOTES}

12a. DISTRIBUTION/AVAILABILITY STATEMENT National Technical Information Service

12b. DISTRIBUTION CODE

U.S. Department of Commerce

5285 Port Royal Road

Springfield, VA 22161

13. ABSTRACT (Maximum 200 words)

The National Renewable Energy Laboratory conducted an experiment to obtain detailed wind measurements and corresponding wind turbine measurements in order to establish a causal relationship between coherent turbulent structures and wind turbine blade fatigue loads. Data were collected for one entire wind season from October 2000 to May 2001. During this period, the wind turbine operated under atmospheric conditions that support the formation of coherent turbulent structures $31 \%$ of the time. Using the equivalent fatigue load parameter as a measure of wind turbine blade fatigue and using statistical measures of the turbulent fluctuations of the wind, general correlation between the turbulence and the wind turbine response is shown. Direct correlation cannot be resolved with 10-minute statistics for several reasons. Multiple turbulent structures can exist within a 10-minute record, and the equivalent fatigue load parameter is essentially a 10-minute statistic that cannot estimate turbine response to individual turbulent structures. Largemagnitude turbulent fluctuations in the form of instantaneous Reynolds stresses do not necessarily correspond directly to large-magnitude blade root moment amplitudes. Thus, additional work must be done to quantify the negative turbine response and to correlate this response to turbulent inflow parameters over time scales less than 10 minutes.

14. SUBJECT TERMS wind turbines; turbulence; fatigue

15. NUMBER OF PAGES

16. PRICE CODE

17. SECURITY CLASSIFICATION OF REPORT Unclassified
18. SECURITY CLASSIFICATION OF THIS PAGE Unclassified
19. SECURITY CLASSIFICATION OF ABSTRACT Unclassified
20. LIMITATION OF ABSTRACT

UL
NSN 7540-01-280-5500

Standard Form 298 (Rev. 2-89) Prescribed by ANSI Std. Z39-18 